\title{
WAR IS GOD'S WAY OF TEACHING GIS
}

\author{
Jerome E. Dobson \\ Research Professor \\ Kansas Applied Remote Sensing Program \\ University of Kansas
}

When people recall the morning of September 11, 2001, most speak of horror, sadness, and shock. My own vivid recollection is of horror and sadness, but not shock. Instead, I felt a sickening realization that the inevitable had finally happened, and I was surprised only by the method. Since 1997, my colleagues and I at Oak Ridge National Laboratory (ORNL) had been helping the United States Government and international organizations anticipate and prepare for threats potentially involving far greater numbers of victims than those that actually occurred that morning in New York, Pennsylvania, and Washington, D.C. I left ORNL for my current position at the University of Kansas (KU) less than one month before the 9-11 attacks, and global threats were still on my mind. The topic scheduled for my graduate seminar that very day was "estimating populations at risk."

\section{Global Coverage}

The "New World Order" has come to mean "global threats to local places." Terrorism and regional conflicts have joined natural disasters and technological accidents as ubiquitous threats that can strike anywhere on earth and yet impact areas as small as a neighborhood, city block, or single building. Population estimates are essential for mission planning to determine how many emergency personnel to send, how much temporary shelter to provide, and what quantities of emergency supplies are needed. An over-estimate costs resources, but underestimates cause unnecessary suffering and may cost lives. Geographic analysis, increasingly based on modern geographic information systems (GIS) and satellite remote sensing, is essential to improving such estimates.

Funded by the U. S. Department of Defense (DoD), the LandScan team I headed at ORNL was responsible for developing a global population database at a spatial resolution fine enough to identify populations actually or potentially impacted by all sorts of global threats to local places. The LandScan Global Population Database was demonstrated for a single country in 1997, completed for the whole world for calendar year 1998, and updated for 2000 and 2001 (Dobson et al., 2000; forthcoming 2003). By the time I left ORNL, the database had been adopted by DoD, the U.S. Department of State, the United Kingdom's Ministry of Defense, several agencies of the United Nations - the World Health Organization, Food and Agriculture Organization, High Commission on Refugees, and ReliefWeb - and other national and international organizations as 
a de facto world standard for estimating populations at risk from terrorism, technological accidents, regional conflicts, and natural disasters. Actual applications included the accidental release of radiation from a nuclear power plant in Japan and the horrendous flooding of Mozambique in Spring 2000. Hypothetical scenarios ranged from biological agents wafting across a few city blocks to nuclear exchanges affecting whole regions.

The spatial resolution of the global LandScan database is 30 arc seconds of latitude by 30 arc seconds of longitude. That equals about 1 square kilometer per cell at the equator and grows finer toward the poles. The previous world standard for estimating populations at risk was 20 arc minutes of latitude by 30 arc minutes of longitude, or 2,400 square kilometers per cell at the equator. LandScan thus represents a quantum leap in precision, made possible by a remarkable jump in the public availability of global databases in the late 1990's and recent advances in geographic information systems (GIS). Modern GIS technologies would have been powerless, however, without traditional geographic analysis techniques. Best available aggregate census counts, provided by the International Programs Center of the U. S. Bureau of the Census, were distributed to LandScan cells through dasymetric interpolation, a cartographic modeling technique invented by John K. Wright of the American Geographical Society more than 65 years ago (Wright 1936).

LandScan provides a 24-hour ambient population estimate, undistinguished by nighttime, daytime, seasonal, or other mobility factors. As with any population database, it can serve a vast number of applications, and most of them do not involve threats. A telecommunications company, for instance, acquired LandScan to determine optimal locations for cell phone towers. Its popularity for emergency management and humanitarian response derives from the fact that its database structure and spatial resolution were designed specifically to suit key software programs used by the U.S. military to project air plumes associated with chemical, biological, and nuclear releases. The LandScan project, now under E. A. Bright's leadership, continues to provide global population data for free online.

LandScan2000 is online at: http://sedac.ciesin.columbia.edu/plue/gpw/landscan LandScan2001 is at: http://www.ornl.gov

City Block Resolution in the U.S.

Even finer resolutions are needed for many types of disasters. To illustrate, simply recall how desperate New York City's first responders were to know how many people likely were in the World Trade Center that fateful morning. No reliable estimate was available, however, because the U.S. Census, like most official censuses around the world, counts people where they sleep, not where they work. Months before my departure from ORNL, we proposed LandScanUSA with daytime and nighttime population estimates at 3 arc seconds, or 100 times more precise than the global LandScan database 
(Dobson et al., forthcoming 2003). We chose Houston, Texas, and 29 surrounding counties in Texas and Louisiana as our initial study area. There we demonstrated that such fine resolution is possible for the U.S. due to its established collection of high-resolution spatial databases. Through dasymetric interpolation we disaggregated block-level Census 2000 populations (by age and sex characteristics) to LandScanUSA cells. That is equivalent to having the finest city block resolution for the entire countryside. In this particular study area, less than 0.1 per cent of city blocks are smaller than 3 arc seconds by 3 arc seconds, and most are substantially larger. Indeed, 89 per cent of the land area exists in blocks even larger than the global LandScan cells (30 arc seconds by 30 arc seconds). Daytime populations are estimated by adjusting for block-toblock worker flows, placing school-age children in elementary and high schools, keeping prisoners in prison, modeling traffic flows on streets and highways, estimating the number of "shoppers" in commercial areas, and retaining the rest in their census residences.

In retrospect, of course, we wish we had chosen New York for our demonstration. Instead, on September 11 emergency managers had no choice but to reject the (nighttime) census block count (55 people in the large block containing the World Trade Center) and make educated guesses that turned out to be 2 to 4 times greater, respectively, than the actual number of people at risk and the actual number of deaths. Since then, ORNL has received funding to develop LandScanUSA for many of the nation's larger cities.

\section{City Block Resolution Worldwide}

From its beginning, the LandScan project faced ever-increasing pressures from many quarters to make the database finer not just for the United States but for any place on earth. Our LandScan experience convinces us that it's technically feasible to generate a global population database at 15 arc seconds by 15 arc seconds resolution, based on currently available global databases, but no agency has yet funded the effort. Partly, that's because potential sponsors believe the resolution needs to be even finer, more like the city block resolution of LandScanUSA. Hence, no global capability currently exists to estimate populations in buildings, city blocks, or neighborhoods smaller than 30 arc seconds by 30 arc seconds. Presently, I foresee no imminent breakthrough in data availability that will support such spatial resolution worldwide, and daytime versus nighttime mobility factors are out of the question in all but a few advanced nations. Yet, national and international organizations, especially the United Nations (UN), often must conduct humanitarian missions anywhere in the world in response to such local incidents.

Faced with overwhelming need and the impossibility of producing a suitable global database, I concluded the only hope was to develop a technique that could be employed in real-time once the location and extent of any given

disaster or potential disaster was known. I decomposed the problem into two 
parts: 1) estimating how many people typically occupy each type of building by day or night and 2) measuring how much floor space is available for occupation. That second component - measuring floor space through field observation, map analysis, or image analysis - is the labor-intensive part that prohibits worldwide application. It's best done for specific locations where the disaster or potential disaster is known, and the need is clear and compelling. The first part, however, must be done with forethought for large world regions, and that is the part we tackled.

Our approach is based on field observation in each world region to determine typical floor plans of 35 or more functional building types (single family dwelling, hut, shanty, store, kiosk, restaurant, hospital, etc.). For each general building type, field observations are made to determine typical numbers of occupants at full capacity. Ultimately, the enclosed area is divided by the number of occupants to create a coefficient that can be applied per square meter of space. Coefficients are distinguished by day and night, but not by precise hour of the day. Coefficients for certain episodic events, such as church services, are estimated as well. The resulting coefficients apply to any local area within each general region. Once the precise location of a disaster is known, the building sizes and types can be determined through remote sensing aided by in situ observations conducted by the responsible agencies. A population estimate can then be derived by multiplying the building area times the number of floors times the appropriate coefficient for that building type for day vs. night or episodic event. The resulting data and associated improvements in population estimation procedures will greatly improve national and international capabilities to estimate casualties and assess damage for disaster areas of all types and for refugees in transit or in camps.

In 1999, A. L. King and I demonstrated the efficacy of this new technique for test areas in the U. S. In 2000, R. W. Peplies and I implemented the technique in the Horn of Africa, and in 2001 we implemented it for Northwestern South America. Current funding will extend coverage to the Balkans, Middle East, and Far East over the coming year.

Our approach is a revival and enhancement of methods used by settlement geographers principally from about 1920 to 1970 . During that era, diverse geographical studies were made of building forms, types, and styles. Albert Demangeon (1872-1940) examined vernacular dwelling designs, sometimes including detailed floor plans. Fred Kniffen (1901-1993) focused on characteristic folk styles of housing, barns, fences, and outbuildings. Kirk Stone (1914-1997) focused on the spatial organization of settlements. Of these three leading experts, Demangeon's observations of building designs came closest to the type of observation adopted here. His purpose was different, however, and he did not measure the area of enclosed spaces and calculate population densities. 
R. W. Peplies and I view this application as a new call for settlement geography of a type that all but disappeared in the last quarter of the previous century. Throughout the previous era of settlement studies, there was a conspicuous emphasis on the developed world. Hardly any extant studies focus on less developed nations. We hope to extend our enhanced approach to the entire world.

\section{Geography in the War on Terrorism}

Comedian Paul Rodriquez once said, "War is God's way of teaching geography." No truer words have ever been spoken. He meant place name geography, no doubt, but the same principle applies to geography as a science, as a professional field of research and analysis, and now as GIS. During World War I, the American Geographical Society (AGS) ran "the Inquiry" - a multidisciplinary information gathering, scientific integration, geographic analysis, and foreign policy venture commissioned personally by President Woodrow Wilson. During World War II, one-third of all academic geographers moved to Washington, D.C. to work in the Office of Strategic Services (OSS) and other federal agencies. Today, geographers and GIS analysts are contributing mightily to the war against terrorism.

The LandScan Global Population Database has been acknowledged as an important foundation to many counter-terrorism and humanitarian response efforts. That, in turn, has opened avenues for me to witness several modern day heroes of geography in action. The newness of my move from ORNL to KU, coupled with my election as President of the American Geographical Society (AGS) in February 2002, gave me a unique vantage - half observer, half participant - on subsequent events (Dobson 2002). l'd like to share some of those observations with you:

When the attacks came, Executive Director Mary Lynne Bird and the AGS staff were in our headquarters at 120 Wall Street. They remained until the order came to evacuate. At midday, they were instructed simply to "start walking north." Officers, Councilors, Fellows, and friends waited anxiously for word that all had arrived home safely. Not until they were allowed to return to the office several days later, could they and we rest assured the facility itself was unharmed.

In October, I gave a lecture, scheduled long before 9-11, at the Centers for Disease Control in Atlanta, where LandScan was being considered as a boon to epidemiology. Within days, my host Jerry Curtis was called to Washington to help in the Anthrax investigation at the Brentwood Postal Facility. For about three weeks, we communicated frequently, and I witnessed from afar as he struggled with and overcame the technical and institutional difficulties of conducting an extremely fine resolution GIS analysis inside the facility. 
On November 11, my family and I visited Ground Zero in New York City while most of the debris was still in place. The next day, I visited the temporary Emergency Operations Center on Pier 92 to see the Geographic Information Systems (GIS) facility that had been hastily assembled on September 11 by Sean Ahearn and 50 or more heroic geographers and GIS analysts. By coincidence, I was there when American Airlines \#587 crashed on Long Island. I watched firemen and policemen urgently request maps and images of Belle Harbor, Long Island, and I watched Chris Schielein and others satisfy those demands in less than 30 minutes. All bridges, tunnels, and airports were closed for most of the day, but my wife and I flew out on one of the first jets to leave JFK Airport that evening.

Throughout the year I was called by various federal and international agencies to comment on the quality of LandScan data in various countries around the world. That kept me in contact with people who are working to monitor the refugee crisis in Southcentral Asia and, notably, with Chris Auricht of the UN Food and Agriculture Organization, who used LandScan to help plan the seed supply for the spring planting in Afghanistan.

Throughout the year, I encountered several federal agencies and private corporations struggling with internal GIS development. In each case, some in-house geographer or GIS analyst sacrificed his or her own interests to force revolutionary changes on a stodgy bureaucracy. Those heroes must remain unnamed.

\section{University Strategies in a Time of National and Global Emergency}

GIS is increasingly demanded in funded research projects. Of all National Science Foundation awards granted last year, for instance, $\$ 140,000,000$ went to projects involving GIS in one way or another. To understand the current boom in academic research opportunities, it helps to understand what is happening commercially. The world market for GIS has grown rapidly and continuously since the technology first appeared two decades ago. In 2000, global revenue hit $\$ 6.9$ billion, and an estimated 2,000,000 users operated 500,000 systems worldwide. Annual growth rates for software (15-20\%) and services (10-15\%) were impressive, and the current national crisis increases demands for homeland and national security, even at this time of economic recession. According to Daratech, a leading market survey company, current market trends are topped by expansion into "new disciplines, industries, markets, and applications." Identical trends are evident in academe.

Universities clearly have a vital role to play in post 9-11 recovery and prevention of future catastrophes, especially in terms of geographic research and education. Geography, GIS, and remote sensing will be essential to the analysis 
and prediction of global threats to local places. Ultimately, GIS is essential to a wide variety of local, state, and federal applications including homeland and national security, emergency management, resource and environmental management, energy development, hazardous waste management, policy analysis, and improved understanding of global threats to local places.

\section{References}

Dobson, J. E. (2002). GIS Supports the War on Terrorism in Many Ways. GeoWorld, vol. 15, no. 1.

Dobson, J. E., Bright, E. A., Coleman, P. R., and Bhaduri, B. L. (forthcoming 2003). LandScan2000: A New Global Population Geography, chapter 15 in V. Mesev (Ed.), Remotely-Sensed Cities. London: Taylor \& Francis, Ltd.

Dobson, J. E., Bright, E. A., Coleman, P. R., Durfee, R.C., and Worley, B. A. (2000). LandScan: A Global Population Database for Estimating Populations at Risk, Photogrammetric Engineering and Remote Sensing, 66 (7), 849-857.

Wright, J. K. (1936). A Method of Mapping Densities of Population with Cape Cod as an Example, Geographical Review, 26, 103-110. 